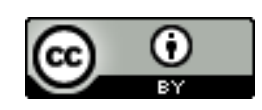

Esta obra está sob o direito de Licença Creative Commons Atribuição 4.0 Internacional.

\title{
A LUDICIDADE E SUAS CONTRIBUIÇÕES PARA O ENSINO-APRENDIZAGEM
}

\author{
Rubiana de Omena Gusmão Moreno da Rocha ${ }^{1}$ \\ Betijane Soares de Barros ${ }^{2}$ \\ Luciana de Omena Gusmão ${ }^{3}$ \\ Rosineide Maria Rocha Tavares ${ }^{4}$ \\ Franyne Pedrosa da Silva ${ }^{5}$ \\ Léa Karla Carvalho P. Barros ${ }^{6}$
}

\section{RESUMO}

A falta de conhecimento sobre a ludicidade é um problema compartilhado por todos aqueles que se omitem a não fazer uso dessa ferramenta. As crianças e os pais devem conhecer a ludicidade e saber como evitar problemas desnecessários. Na presente investigação, a análise inovadora é a ludicidade e seu impacto na educação, a fim de revelar a importância de presente tópico e sua incidência na produção de melhorias no sistema Ensino-Aprendizagem para educação. A ludicidade busca educar as crianças com alegria e carinho, desenvolvendo senso de responsabilidade, autonomia por si e pelos outros, é um tema que adquire crescente relevância científica. O presente trabalho analisou produções científicas publicadas entre 2016 e 2021, nos sites: Scielo, Periódicos da Capes e Wiley. O objetivo desta pesquisa foi identificar as contribuições da ludicidade para o ensino-aprendizagem. Trata-se de uma revisão sistemática. Os descritores estruturados no DeCS e MeSH. O período de coleta dos dados correu no mês de janeiro de 2021. Adotaram-se como critérios de inclusão artigo científicos sobre a temática. Enquanto que os critérios de exclusão foram artigos científicos que não contemplam a temática sobre a ludicidade. Espera-se que com novos estudos ocorro um novo olhar direcionado a melhoria da ludicidade relacionada a aspectos satisfatória, pois a mudança operada pela ludicidade com as crianças é promovendo assim uma educação de qualidade e prezerosa.

Palavras-chave: Ludicidade. Educação. Lúdico. Ensino-aprendizagem.

\footnotetext{
${ }^{1}$ rubianaomena@hotmail.com

2 bj.sb@hotmail.com

${ }^{3}$ log.gusmao2010@gmail.com

${ }^{4}$ rosineidetavares0209@gmail.com

5 francynepedrosa@outlook.com

6 leakarlaeducacaoespecial@gmail.com
} 


\section{INTRODUÇÃO}

A definição de lúdico, jogo foi definido de várias formas durante muitos anos. Com base nosso podemos dizer em geral que o Lúdico não é apenas uma brincadeira, mas sim a liberdade de expressão física e emocional, é a abertura para novos conhecimentos. Viver ludicamente significa uma forma de descoberta do mundo, indica que não apenas estamos inseridos nele, mas, sobretudo, que somos parte de todo seu conhecimento prático e que essas reflexões são as nossas ferramentas para compreendêlo e interagir com ele (REGINATO, 2016).

À medida que a criança cresce é por meio da brincadeira que ela se comunica com o outro e aprende a se relacionar, é através das brincadeiras e da relação com o brinquedo que ela expressa seus sentimentos, por isto podemos dizer que eles são o elemento transmissor e dinamizador de costumes e condutas destas (PEREIRA, 2017).

Para a elaboração de um conhecimento, precisa-se de uma relação entre o sujeito com o objeto estudado além de certa formação de conceitos cognitivos e ligações adquiridas com o mundo físico, isto é a elaboração de relações cada vez mais totalizantes. Para o ensino e a aprendizagem foi traçado um paralelo entre o brinquedo e a instrução escolar, onde de esta forma a criança elabora habilidades e conhecimentos socialmente disponíveis que passará a internalizar. Para que ocorra o processo de ensino e aprendizagem de conhecimento que lhe será passado a uma criança é preciso que haja uma elaboração explícita e sintética do conhecimento para que ocorra a aprendizagem, portanto o educando terá que fazer uma síntese, ou seja, uma análise do seu conhecimento adquirido em sala de aula para a construção do conhecimento que será transmitido (INÁCIO, et al. 2016). Portanto a atuação do professor deve estar voltada para a utilização de metodologias que facilitem aos seus aprendizes a aquisição de uma estrutura cognitiva adequada, onde os conceitos mais amplos das diversas áreas do conhecimento sejam claramente estabelecidos (ANUNCIAÇÃO, ARANTES e CHIRINÉA, 2016).

Especificamente as crianças de $1^{\mathrm{a}}$ a $4^{\mathrm{a}}$ série passam por um período algo conturbado, já que é uma face de transição da pré-escola para o ensino fundamental, aonde estes irão novos aprendizados e objetivos diferentes. $O$ ensino de $1^{\mathrm{a}}$ a $4^{\mathrm{a}}$ série, ensino fundamental ou series iniciais do ensino fundamental é um ensino obrigatório no Brasil, que compreende crianças de 6 e 14 anos. Essa etapa chamada de educação básica deve desenvolver a capacidade do aluno a aprender a ler, escrever e fazer cálculos, por isto é 
obrigatória no Brasil, pois é onde se inicia a alfabetização da criança (COUTINHO, 2009).

Ao modo em que esse processo professor-aluno deve ser trabalhado em conjunto, já que se nessa face de transição da criança de um espaço educativo a outro

\section{METODOLOGIA}

Trata-se de uma revisão sistemática, que seguiu as seguintes etapas (ver Figura 1): definição do tema; seleção da pergunta norteadora e escolha da estratégia de busca; descritores e bases de dados mais eficazes no levantamento das publicações; escolha dos critérios de inclusão e exclusão; identificação dos estudos pré-selecionados e selecionados por meio da leitura dos agentes indexadores das publicações, como resumos, palavras-chave e títulos, bem (ensino infantil á ensino fundamental) não for tratada de forma correta podem provocar perturbações emocionais e dificuldades cognitivas e de relacionamento com os sujeitos ao seu redor (ESPINDOLA, 2017).

como a organização dos estudos préselecionados e a identificação dos estudos selecionados; categorização dos estudos selecionados, com a elaboração e o uso da matriz de síntese, além da análise das informações; a formação de uma biblioteca individual e a avaliação crítica dos estudos selecionados; análise, interpretação e discussão dos resultados e a apresentação da revisão em formato de artigo, o qual contempla as propostas para estudos futuros.

Quadro 1 - Detalhamento das etapas da Revisão Sistemática.

\begin{tabular}{|c|c|c|c|c|}
\hline ETAPA & $\begin{array}{l}\text { TÓPICOS } \\
\text { DE CADA } \\
\text { ETAPA }\end{array}$ & \multicolumn{3}{|c|}{ DETALHAMENTO DE CADA TÓPICO } \\
\hline \multirow[t]{10}{*}{$1^{\mathrm{a}}$} & Tema & \multicolumn{3}{|c|}{ A ludicidade e suas contribuições para o ensino-aprendizagem } \\
\hline & $\begin{array}{c}\text { Pergunta } \\
\text { norteadora }\end{array}$ & \multicolumn{3}{|c|}{ Qual a contribuição da ludicidade para o ensino-aprendizagem? } \\
\hline & $\begin{array}{c}\text { Objetivo } \\
\text { geral }\end{array}$ & \multicolumn{3}{|c|}{ Identificar as contribuições da ludicidade para o ensino-aprendizagem. } \\
\hline & $\begin{array}{c}\text { Estratégias de } \\
\text { busca }\end{array}$ & \multicolumn{3}{|c|}{$\begin{array}{l}\text { Cruzamento de descritores por meio do operador booleano AND; } \\
\text { Uso de descritores estruturados (codificação) no DECS ou MESH; } \\
\text { Uso de metadados (filtros). }\end{array}$} \\
\hline & \multirow{3}{*}{$\begin{array}{c}\text { Bancos de } \\
\text { terminologias }\end{array}$} & BANCO & & LINK \\
\hline & & DeSC & http://decs.bvs.br/ & \\
\hline & & $\mathrm{MeSH}$ & https://www.ncbi.n & a.gov/mesh \\
\hline & \multirow{3}{*}{$\begin{array}{l}\text { Descritores } \\
\text { livres e } \\
\text { estruturados }\end{array}$} & Descritor & DeSC (Registro) & MeSH (Identificador Único) \\
\hline & & Docência & 14042 & $\mathrm{D} 013663$ \\
\hline & & Ludicidade & 11416 & D010988 \\
\hline
\end{tabular}




\begin{tabular}{|c|c|c|c|c|c|c|}
\hline & & \multicolumn{2}{|c|}{ Fundamental } & \multicolumn{2}{|c|}{35173} & DCS035173 \\
\hline & $\begin{array}{l}\text { String de } \\
\text { busca }\end{array}$ & \multicolumn{5}{|c|}{$\begin{array}{c}\text { Docência AND ludicidade } \\
\text { Ensino fundamental AND ludicidade }\end{array}$} \\
\hline & \multirow{6}{*}{$\begin{array}{l}\text { Bibliotecas } \\
\text { Virtuais }\end{array}$} & \multicolumn{5}{|c|}{ Link } \\
\hline & & & Wiley & \multicolumn{3}{|c|}{ https://onlinelibrary.wiley.com/ } \\
\hline & & & ience Direct & \multicolumn{3}{|c|}{ https://www.sciencedirect.com/ } \\
\hline & & & BVS & \multicolumn{3}{|c|}{ https://bvsalud.org/ } \\
\hline & & & Scielo & \multicolumn{3}{|c|}{ https://search.scielo.org/ } \\
\hline & & & $\begin{array}{l}\text { eriodicos da } \\
\text { Capes }\end{array}$ & \multicolumn{3}{|c|}{ https://www.periodicos.capes.gov.br/ } \\
\hline \multirow[t]{3}{*}{$2^{\mathrm{a}}$} & $\begin{array}{l}\text { Período de } \\
\text { coleta dos } \\
\text { dados }\end{array}$ & \multicolumn{5}{|c|}{ Junho de 2020} \\
\hline & $\begin{array}{l}\text { Critérios de } \\
\text { inclusão }\end{array}$ & \multicolumn{5}{|c|}{$\begin{array}{l}\text { Texto (artigo científicos). } \\
\text { Publicação (2015-2020). }\end{array}$} \\
\hline & $\begin{array}{l}\text { Critérios de } \\
\text { exclusão }\end{array}$ & \multicolumn{5}{|c|}{ Artigos que não contemplam a temática "Ludicidade". } \\
\hline $3^{a}$ & \multicolumn{5}{|c|}{$\begin{array}{l}\text { Número de trabalhos selecionados para revisão sistemática a } \\
\text { partir da leitura dos agentes indexadores das publicações } \\
\text { (tema, descrição, ementa). }\end{array}$} & 21 \\
\hline $4^{\mathrm{a}}$ & \multicolumn{5}{|c|}{$\begin{array}{c}\text { Categorias obtidas com a análise dos documentos investigados } \\
\text { online gratuitos e de livre acesso. }\end{array}$} & 4 \\
\hline \multirow[t]{2}{*}{$5^{a}$} & \multirow{2}{*}{\multicolumn{2}{|c|}{$\begin{array}{c}\text { Tecnologias } \\
\text { digitais utilizadas }\end{array}$}} & \multicolumn{2}{|c|}{$\begin{array}{c}\text { Tecnologia } \\
\text { (software ou website) }\end{array}$} & Link & Utilidade \\
\hline & & & \multicolumn{2}{|c|}{$\begin{array}{l}\text { WordArt: Nuvem de } \\
\text { palavras }\end{array}$} & $\frac{\text { https://wordart.com }}{I}$ & $\begin{array}{c}\text { Construir nuvem de } \\
\text { palavras e frequência } \\
\text { das palavras-chave } \\
\text { para criar as } \\
\text { categorias temáticas. }\end{array}$ \\
\hline
\end{tabular}

Fonte: elaborada pelos autores.

\section{RESULTADOS}

Quadro 2 - Corresponde ao total de documentos disponíveis nas Plataforma BVS, Scielo e Periodicos da Capes, obtidos por string de busca.

\begin{tabular}{|c|c|c|c|c|}
\hline String de busca & $\begin{array}{c}\text { Bases de dados } \\
\text { Plataforma }\end{array}$ & $\begin{array}{c}\text { Total de } \\
\text { publicações } \\
\text { sem o filtro }\end{array}$ & $\begin{array}{c}\text { Publicações } \\
\text { disponíveis } \\
\text { após aplicar } \\
\text { os filtros }\end{array}$ & $\begin{array}{c}\text { Publicações } \\
\text { aproveitadas na } \\
\text { Revisão } \\
\text { Sistemática }\end{array}$ \\
\hline $\begin{array}{c}\text { Docência AND } \\
\text { ludicidade } \\
\text { Teaching AND } \\
\text { playfulness }\end{array}$ & $\begin{array}{c}\text { Periódicos da } \\
\text { Capes }\end{array}$ & 27 & 1 & 1 \\
\hline $\begin{array}{c}\text { Ensino } \\
\text { fundamental AND } \\
\text { ludicidade }\end{array}$ & Wiley & 4 & 1 & 3 \\
\cline { 2 - 5 } Elementary school & Scielo & 6 & 5 & 1 \\
\cline { 2 - 5 } AND playfulness & Capiódicos da & 141 & 78 & 14 \\
\hline
\end{tabular}


Fonte: elaborada pelos autores.

Foram detectadas 180 publicações científicas nos bancos de dados, das quais 78 eram artigos disponíveis após o uso dos filtros, desses foram feitos 21 downloads, que obedeceram aos critérios de inclusão, sendo submetidos às etapas da revisão sistemática.

Quadro 3 - Descrição dos documentos (artigos) de acordo com os critérios de inclusão.

\begin{tabular}{|c|c|c|c|c|}
\hline $\mathbf{N}^{\mathbf{0}}$ & AUTOR(A) & TEMA & ANO & CONCLUSÃO \\
\hline 1 & $\begin{array}{l}\text { Catarina Joelma } \\
\text { Magalhães } \\
\text { Lydia Dayanne Maia } \\
\text { Pantoja } \\
\text { Tatiana Paschoalette } \\
\text { Rodrigues Bachur } \\
\text { Gislei Frota Aragão }\end{array}$ & $\begin{array}{l}\text { Jogo de cartas como } \\
\text { estratégia para o ensino de } \\
\text { doenças autoimunes na } \\
\text { graduação médica }\end{array}$ & 2019 & $\begin{array}{l}\text { A utilização do jogo } \\
\text { facilitou a fixação dos } \\
\text { conteúdos e favoreceu o } \\
\text { processo de ensino- } \\
\text { aprendizagem ao permitir } \\
\text { múltiplas interações, } \\
\text { promover a aprendizagem } \\
\text { dos conteúdos, desenvolver } \\
\text { autonomia, criatividade, } \\
\text { cooperação aú } \\
\text { discussões e tomadas de } \\
\text { decisões, } \\
\text { indispensáveis aosilidades } \\
\text { médicos. }\end{array}$ \\
\hline 2 & $\begin{array}{l}\text { Sergio Bruno F. } \\
\text { Saraiva } \\
\text { Braulio Nogueira de } \\
\text { Oliveira, João Lucas P. } \\
\text { Matias, Bérgson } \\
\text { Nogueira de Oliveira } \\
\text { André A. Nogueira } \\
\text { Machado e Antônio } \\
\text { Ricardo C. de Oliveira }\end{array}$ & $\begin{array}{c}\text { CONHECIMENTOS } \\
\text { LUDOPEDAGÓGICOS NA } \\
\text { APRENDIZAGEM DA } \\
\text { NATAÇÃO INFANTIL }\end{array}$ & 2018 & $\begin{array}{l}\text { Conclui-se que é preciso } \\
\text { fomentar a manifestação do } \\
\text { componente lúdico como } \\
\text { forma de potencializar a } \\
\text { fruição, o processo } \\
\text { educativo e a participação } \\
\text { criativa na cultura. }\end{array}$ \\
\hline 3 & $\begin{array}{l}\text { Vânia Aparecida } \\
\text { Calado } \\
\text { Herculano Ricardo } \\
\text { Campos }\end{array}$ & $\begin{array}{c}\text { A formação inicial do } \\
\text { pedagogo e o enfrentamento } \\
\text { da medicalização na } \\
\text { educação }\end{array}$ & 2018 & $\begin{array}{l}\text { A avaliação realizada depois } \\
\text { de compartilhar diferentes } \\
\text { brincadeiras, leitura de } \\
\text { textos, poemas e estudos de } \\
\text { casos sobre medicalização } \\
\text { na educação revelou que } \\
\text { essa mediação pedagógica } \\
\text { contribuiu para qualificar a } \\
\text { compreensão } \\
\text { estudantes. }\end{array}$ \\
\hline 4 & $\begin{array}{l}\text { Lucas Leonardo } \\
\text { Alcides José Scaglia }\end{array}$ & $\begin{array}{c}\text { ESTUDO SOBRE } \\
\text { REGULAMENTOS NO } \\
\text { HANDEBOL DE JOVENS: } \\
\text { UMA ANÁLISE } \\
\text { DOCUMENTAL SOBRE O } \\
\text { USO OBRIGATÓRIO DO } \\
\text { SISTEMA DEFENSIVO } \\
\text { INDIVIDUAL EM }\end{array}$ & 2018 & $\begin{array}{l}\text { A possibilidade de } \\
\text { exploração de maiores } \\
\text { espaços defensivos } \\
\text { pressupõe a existência de } \\
\text { punições para inibir trapaças } \\
\text { e atitudes transgressoras de } \\
\text { treinadores e atletas em } \\
\text { busca do cumprimento da }\end{array}$ \\
\hline
\end{tabular}




\begin{tabular}{|c|c|c|c|c|}
\hline & & $\begin{array}{l}\text { COMPETIÇÕES SUB-12 E } \\
\text { SUB-14 }\end{array}$ & & $\begin{array}{l}\text { lógica ofensiva e defensiva } \\
\text { do jogo. }\end{array}$ \\
\hline 5 & Ângela Barcellos Café & $\begin{array}{c}\text { O JOGO LÚDICO NA } \\
\text { ESCOLA DE ENSINO } \\
\text { BÁSICO }\end{array}$ & 2018 & $\begin{array}{l}\text { As considerações finais } \\
\text { apontam para uma } \\
\text { convergência } \\
\text { possibilidades de atuação } \\
\text { lúdica na escola, utilizando o } \\
\text { jogo, brinquedo ou } \\
\text { brincadeira em qualquer das } \\
\text { áreas do conhecimento, } \\
\text { considerando as } \\
\text { características de: estratégia, } \\
\text { desenvolvimento } \\
\text { conhecimento, para um } \\
\text { ensino/aprendizagem mais } \\
\text { significativos. }\end{array}$ \\
\hline 6 & $\begin{array}{l}\text { Débora Jaqueline } \\
\text { Farias Fabiani } \\
\text { Alcides José Scaglia } \\
\text { José Júlio Gavião de } \\
\text { Almeida }\end{array}$ & $\begin{array}{c}\text { O JOGO DE FAZ DE } \\
\text { CONTA E O ENSINO DA } \\
\text { LUTA PARA } \\
\text { CRIANÇAS: CRIANDO } \\
\text { AMBIENTES DE } \\
\text { APRENDIZAGEM } \\
\end{array}$ & 2016 & $\begin{array}{l}\text { Posto isto, apresentamos } \\
\text { estratégias pedagógicas que } \\
\text { consideram }\end{array}$ \\
\hline 7 & $\begin{array}{l}\text { Nair Casagrande } \\
\text { Fernanda Lima Ramos }\end{array}$ & $\begin{array}{c}\text { A EDUCAçãO FíSICA NO } \\
\text { CONTEXTO } \\
\text { DA EDUCAÇÃO DO } \\
\text { CAMPO: a realidade } \\
\text { do conteúdo jogo na escola }\end{array}$ & 2017 & $\begin{array}{l}\text { Os resultados evidenciam } \\
\text { que, apesar da Educação } \\
\text { Física não constar como } \\
\text { componente curricular no } \\
\text { projeto político-pedagógico } \\
\text { da escola, o conteúdo "jogo" } \\
\text { estava presente na prática } \\
\text { pedagógica da professora da } \\
\text { turma multisseriada. } \\
\text { Contudo, este vinha sendo } \\
\text { utilizado na escola } \\
\text { predominantemente como } \\
\text { um instrumento de ensino ou } \\
\text { como atividade recreativa. }\end{array}$ \\
\hline 8 & $\begin{array}{l}\text { umberto Luís de Deus } \\
\text { Inácio1 } \\
\text { Dayse Alisson Camara } \\
\text { Cauper2 } \\
\text { Luzia Antônia de } \\
\text { Paula Silva3 } \\
\text { Gleison Gomes de } \\
\text { Morais }\end{array}$ & $\begin{array}{l}\text { PRÁTICAS CORPORAIS } \\
\text { DE AVENTURA NA } \\
\text { ESCOLA: possibilidades e } \\
\text { desafios - reflexões para } \\
\text { além da Base nacional } \\
\text { Comum Curricular }\end{array}$ & 2016 & $\begin{array}{l}\text { Concluímos } \\
\text { importância deste conteúdo } \\
\text { e advogamos que sua } \\
\text { inclusão na Educação Física } \\
\text { Escolar deva ser balizada } \\
\text { por propostas pedagógicas } \\
\text { críticas. }\end{array}$ \\
\hline 9 & $\begin{array}{l}\text { Vânia Sofía Pereira*, } \\
\text { José Eugenio } \\
\text { Rodríguez } \\
\text { Fernández**, } \\
\text { Beatriz Pereira*, } \\
\text { Isabel Condessa*** }\end{array}$ & $\begin{array}{c}\text { OS JOGOS DAS } \\
\text { CRIANÇAS NOS } \\
\text { RECREIOS DAS } \\
\text { ESCOLAS DO } 1^{\circ} \text { CICLO } \\
\text { DO ENSINO BÁSICO DO } \\
\text { NORTE DE PORTUGAL }\end{array}$ & 2018 & $\begin{array}{lr}\text { O estudo confirma a pouca } \\
\text { diversificação nos jogos } \\
\text { realizados pelos alunos e, de } \\
\text { acordo com os resultados, é } \\
\text { necessário o enriquecimento } \\
\text { das atividades lúdicas } \\
\text { desenvolvidas pelas crianças } \\
\text { utilizandor novas } \\
\text { intervenções r lúdico- } \\
\text { pedagógicas ou novos }\end{array}$ \\
\hline
\end{tabular}




\begin{tabular}{|c|c|c|c|c|}
\hline & & & & $\begin{array}{l}\text { materiais no espaço de } \\
\text { recreio. }\end{array}$ \\
\hline 10 & $\begin{array}{l}\text { Elaine da Silva Ramos } \\
\text { Fernanda Alves } \\
\text { Campolin dos Santos } \\
\text { Carlos Eduardo } \\
\text { Laburú }\end{array}$ & $\begin{array}{l}\text { O uso da ludicidade como } \\
\text { ferramenta para o Ensino de } \\
\text { Química Orgânica: o que } \\
\text { pensam os alunos }\end{array}$ & 2017 & $\begin{array}{l}\text { Os dados foram analisados } \\
\text { por meio de respostas a } \\
\text { questionários } \\
\text { posteriormente foram } \\
\text { categorizados para a análise } \\
\text { dos resultados, que } \\
\text { apontaram como o jogo e as } \\
\text { atividades lúdicas puderam } \\
\text { auxiliar no processo de } \\
\text { ensino e aprendizagem, e } \\
\text { mostraram também que } \\
\text { essas ferramentas } \\
\text { auxiliaram para que } \\
\text { houvesse um maior diálogo } \\
\text { e interação entre os alunos. }\end{array}$ \\
\hline 11 & $\begin{array}{l}\text { Hélio da Silva } \\
\text { Messeder Neto }\end{array}$ & $\begin{array}{l}\text { O jogo é a excalibur para o } \\
\text { ensino de ciências? } \\
\text { apontamentos para pensar o } \\
\text { lúdico no ensino de } \\
\text { conceitos e na formação do } \\
\text { professor }\end{array}$ & 2019 & $\begin{array}{l}\text { Por fim, é defendida a } \\
\text { importância de caminhar } \\
\text { para um uso mais consciente } \\
\text { e sistemático do lúdico no } \\
\text { ensino de Ciências. }\end{array}$ \\
\hline 12 & $\begin{array}{l}\text { Thayse Geane Iglesias } \\
\text { Camila Silveira }\end{array}$ & $\begin{array}{c}\text { Ensino de ciências e } \\
\text { educação infantil: um estudo } \\
\text { pautado na reprodução } \\
\text { interpretativa e cultura da } \\
\text { infância }\end{array}$ & 2019 & $\begin{array}{l}\text { Observar a criança em sua } \\
\text { ação permite ao docente } \\
\text { explorar essas conclusões, } \\
\text { instigar a curiosidade e a } \\
\text { investigação para que } \\
\text { desenvolvam uma visão } \\
\text { científica do mundo real. }\end{array}$ \\
\hline 13 & $\begin{array}{l}\text { Lúcia Helena Soares } \\
\text { de Oliveira a } \\
\text { Débora Regina Soares } \\
\text { de Oliveira b } \\
\text { Eraldo Gonçalves } \\
\text { Rocha Cézar Junior c } \\
\text { Fabielly Santos } \\
\text { Rodrigues }\end{array}$ & $\begin{array}{c}\text { A LUDICIDADE NO } \\
\text { ENSINO DA GEOMETRIA } \\
\text { NO } 5^{\circ} \text { ANO DO ENSINO } \\
\text { FUNDAMENTAL }\end{array}$ & 2018 & $\begin{array}{l}\text { Encontrou-se, que o Método } \\
\text { Lúdico conseguiu atingir os } \\
\text { objetivos curriculares de } \\
\text { ensino com o uso dos cinco } \\
\text { jogos elaborados } \\
\text { especificamente para este } \\
\text { trabalho contribuindo } \\
\text { significativamente no } \\
\text { processo de ensino- } \\
\text { aprendizagem dos conceitos } \\
\text { de geometria indicados } \\
\text { pelos Parâmetros } \\
\text { Curriculares Nacionais - } \\
\text { PCN para o } 5^{\circ} \text { ano do Ensino } \\
\text { Fundamental. }\end{array}$ \\
\hline 14 & $\begin{array}{l}\text { Andressa Santos } \\
\text { Vogel } \\
\text { Natacha Subtil } \\
\text { Mévelin Maus } \\
\text { Marlete Basso Roman } \\
\text { Sandra Denise } \\
\text { Stroschein }\end{array}$ & $\begin{array}{l}\text { Ensinando polinômios } \\
\text { através da ludicidade }\end{array}$ & 2016 & $\begin{array}{l}\text { Ao final do jogo, os alunos } \\
\text { somaram os resultados de } \\
\text { todas as jogadas, resultando } \\
\text { em um único } \\
\text { monômio/polinômio. } \\
\text { atividade e a utilização de } \\
\text { materiais diversificados } \\
\text { proporcionam } \\
\text { aprendizagem uma } \\
\text { interativa e espontânea, }\end{array}$ \\
\hline
\end{tabular}




\begin{tabular}{|c|c|c|c|c|}
\hline & & & & $\begin{array}{l}\text { facilitando assim o melhor } \\
\text { desempenho dos alunos. }\end{array}$ \\
\hline 15 & $\begin{array}{l}\text { Maria Inês Araújo1 } \\
\text { Solange Mello } \\
\text { Ribeiro2 Beatriz Maria } \\
\text { de Souza3 Iuri Rojahn } \\
\text { da Silva4 }\end{array}$ & $\begin{array}{c}\text { APLICAÇÃO DO JOGO } \\
\text { DE DOMINÓ NA } \\
\text { EDUCAÇÃO } \\
\text { FUNDAMENTAL I: } \\
\text { ELUCIDANDO OS } \\
\text { NUMEROS NO } \\
\text { COTIDIANO DO ALUNO }\end{array}$ & 2016 & $\begin{array}{l}\text { O trabalho envolveu as } \\
\text { operações de adição e } \\
\text { subtração, possibilitando a } \\
\text { construção de conhecimento } \\
\text { matemático. }\end{array}$ \\
\hline 16 & $\begin{array}{l}\text { Daniel Cortes Beretta } \\
\text { Juciene Silva Oliveira } \\
\text { Daniela Costa Vilela }\end{array}$ & $\begin{array}{l}\text { A extensão universitária e a } \\
\text { ludicidade na educação } \\
\text { infantil contra crueldade } \\
\text { animal e violência } \\
\text { interpessoal }\end{array}$ & 2016 & $\begin{array}{l}\text { Como retorno, observou-se } \\
\text { que a maneira lúdica e } \\
\text { educativa foi eficiente em } \\
\text { despertar o interesse das } \\
\text { crianças contra a crueldade } \\
\text { animal, quebrando neste } \\
\text { caso o ciclo insidioso de } \\
\text { violência. }\end{array}$ \\
\hline 17 & $\begin{array}{l}\text { Ana Paula Melo } \\
\text { Fonseca } \\
\text { Lindalva Sâmela } \\
\text { Jacaúna de Oliveira } \\
\text { Augusto Fachín } \\
\text { Terán3 } \\
\text { Gelcimara de Lima } \\
\text { Nobre }\end{array}$ & $\begin{array}{c}\text { A LUDICIDADE NO } \\
\text { ENSINO DE CIÊNCIAS } \\
\text { UTILIZANDO O TEMA } \\
\text { DOS QUELÔNIOS EM } \\
\text { UMA ESCOLA } \\
\text { RIBEIRINHA, } \\
\text { PARINTINS-AM, BRASIL }\end{array}$ & 2018 & $\begin{array}{l}\text { Constatamos que a } \\
\text { ludicidade é importante para } \\
\text { assimilação de conceitos } \\
\text { científicos e a sensibilização } \\
\text { dos estudantes sobre os } \\
\text { problemas ambientais da } \\
\text { comunidade. }\end{array}$ \\
\hline 18 & $\begin{array}{l}\text { Flávia Paula Nogueira } \\
\text { Aranda }\end{array}$ & $\begin{array}{c}\text { AÇÃO DO PIBID- } \\
\text { PEDAGOGIA (UFGD): } \\
\text { INTERVENÇÃO LÚDICA } \\
\text { NA ESCOLA MUNICIPAL } \\
\text { CLARICE BASTOS ROSA } \\
\text { (DOURADOS-MS) }\end{array}$ & 2016 & $\begin{array}{l}\text { As atividades foram } \\
\text { desenvolvidas com turmas } \\
\text { do 2. ano do Ensino } \\
\text { Fundamental, onde a ação } \\
\text { educativa trouxe benefícios } \\
\text { tanto para a docente da sala } \\
\text { de aula, quanto para os } \\
\text { alunos participantes da } \\
\text { atividade. }\end{array}$ \\
\hline 19 & $\begin{array}{l}\text { Álvaro Becker da Rosa } \\
\text { Alisson Cristian } \\
\text { Giacomelli } \\
\text { Cleci T. Werner da } \\
\text { Rosa }\end{array}$ & $\begin{array}{l}\text { Caminhando pelo sistema } \\
\text { solar: análise de uma } \\
\text { atividade lúdica } \\
\text { para estudar escalas } \\
\text { astronômicas }\end{array}$ & 2016 & $\begin{array}{l}\text { Como resultado, o estudo } \\
\text { apontou para a viabilidade } \\
\text { da proposta, mostrando que, } \\
\text { em atividades lúdicas e de } \\
\text { envolvimento ativo dos } \\
\text { estudantes, eles questionam } \\
\text { e indagam de forma mais } \\
\text { significativa e em maior } \\
\text { quantidade que em } \\
\text { atividades expositivas de } \\
\text { sala de aula. }\end{array}$ \\
\hline 20 & $\begin{array}{l}\text { Mikaela de Paula } \\
\text { Lacerda } \\
\text { Giovanna } \\
\text { Moura } \\
\text { Jaqueline } \\
\text { Cavalcanti } \\
\text { Carlos da Silva Cirino }\end{array}$ & $\begin{array}{c}\text { REPRESENTAÇÕES } \\
\text { SOCIAIS DA } \\
\text { LUDICIDADE } \\
\text { ELABORADA POR } \\
\text { PROFESSORES }\end{array}$ & 2017 & $\begin{array}{l}\text { Diante da riqueza de } \\
\text { significados existentes } \\
\text { acerca da ludicidade, essas } \\
\text { representações resultam e } \\
\text { refletem as experiências e } \\
\text { características do grupo } \\
\text { pesquisado. Vale ressaltar } \\
\text { que a importância da } \\
\text { ludicidade deve ser mais } \\
\text { bem compreendida pelos }\end{array}$ \\
\hline
\end{tabular}




\begin{tabular}{|c|c|c|c|c|}
\hline & & & & $\begin{array}{l}\text { professores, pois estes } \\
\text { profissionais são os } \\
\text { mediadores entre a criança e } \\
\text { o brinquedo, brincadeira ou } \\
\text { jogos, e que quando a } \\
\text { ludicidade é usada } \\
\text { pedagogicamente, ela tem } \\
\text { um valor ainda maior na } \\
\text { aprendizagem das crianças. }\end{array}$ \\
\hline 21 & $\begin{array}{l}\text { Rafaela Reginato } \\
\text { Hosokawa; Fabio } \\
\text { Camargo Bandeira } \\
\text { Villela }\end{array}$ & $\begin{array}{c}\text { AGRESSIVIDADE } \\
\text { INFANTIL NO } \\
\text { CONTEXTO ESCOLAR: } \\
\text { AS POSSIBILIDADES DE } \\
\text { AUXÍLIO } \\
\text { PROPORCIONADAS } \\
\text { PELA LUDICIDADE }\end{array}$ & 2016 & $\begin{array}{l}\text { A pesquisa foi realizada com } \\
\text { base nos pressupostos da } \\
\text { pesquisa qualitativa, tendo } \\
\text { como referencial a } \\
\text { investigação } \\
\text { manifestações da criança, } \\
\text { pensadas a partir das } \\
\text { contribuições da teoria } \\
\text { psicanalítica winnicottiana. }\end{array}$ \\
\hline
\end{tabular}

Fonte: Plataformas: Scielo, Periódicos da Capes e Wiley.

O corpo textual foi analisado por meio da frequência de palavras, que originou a nuvem de palavras (Figura 1)

criada na Plataforma online WordArt. Esta ferramenta agrupa e organiza graficamente as palavras-chave evidenciando-as as mais frequentes.

Figura 1. Nuvem de palavras

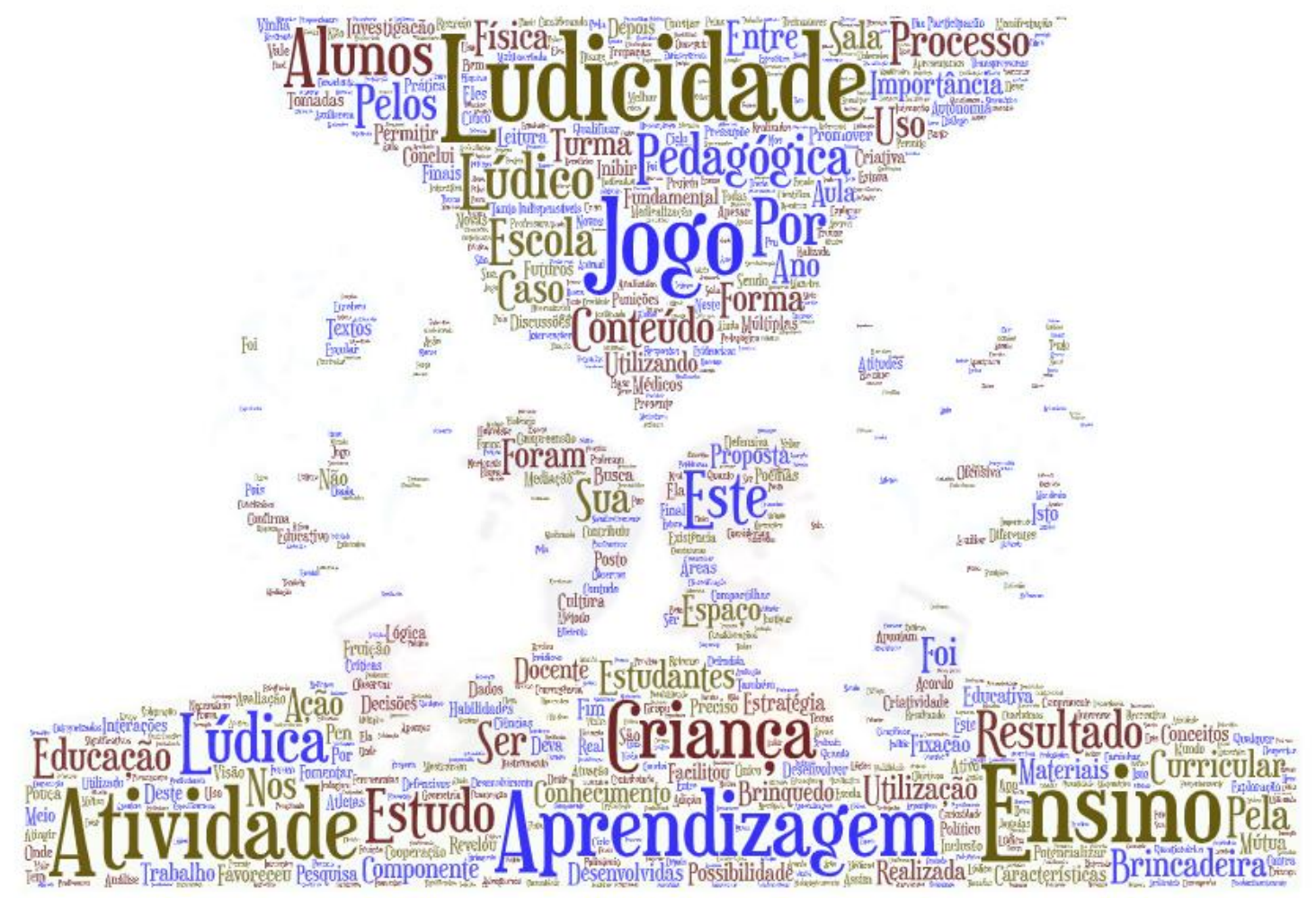

Fonte: autora. 
Por meio da Figura 1, foi possível observar que as palavras em evidência na nuvem pertencem as categorias desenvolvidas a partir da análise de conteúdo de Bardin. Todas as categorias derivam da sua frequência (Tabela 1), que diz respeito ao seu quadro referencial. Em consonância ao objetivo deste trabalho, optou-se por descrever as palavras que apresentaram frequência total no texto e, a partir de seus sentidos nos campos textuais, tinham maior relevância para as representações sociais sobre gênero, como apresentado na Figura1.

Tabela 1. Frequência das palavras presentes nos textos publicados pelos artigos nas Plataformas: Scielo, Periódicos da Capes e Wiley.

\begin{tabular}{l|c|l}
\hline \multicolumn{1}{c|}{ PALAVRAS } & FREQUÊNCIA & \multicolumn{1}{c}{ CATEGORIAS } \\
\hline Lúdico & 6 & Lúdico \\
\hline Ensino/ Aprendizagem & $9 / 9$ & Ensino e aprendizagem \\
\hline Lúdico/Ensino/ Aprendizagem & $6 / 9 / 9$ & $\begin{array}{l}\text { A utilização do lúdico no processo de ensino } \\
\text { e aprendizagem }\end{array}$ \\
\hline $\begin{array}{l}\text { Ludicidade/Ensino/ } \\
\text { Aprendizagem }\end{array}$ & $4 / 9 / 9$ & $\begin{array}{l}\text { As contribuições da ludicidade para o ensino- } \\
\text { aprendizagem }\end{array}$ \\
\hline Lúdico/Ensino/ Aprendizagem & $6 / 9 / 9$ & $\begin{array}{l}\text { Conhecer o lúdico na arte do ensino- } \\
\text { aprendizagem }\end{array}$ \\
\hline $\begin{array}{l}\text { Brincadeira/Ensino/ } \\
\text { Aprendizagem }\end{array}$ & $3 / 9 / 9$ & Aprender brincando o ensino-aprendizagem \\
\hline
\end{tabular}

Fonte: autora.

\section{DISCUSSÃO}

Seguem abaixo, as categorias temáticas elaboradas a partir da revisão sistemática integrativa.

\section{Lúdico}

O lúdico tem sua origem na palavra latina "ludus" que quer dizer "jogo". O lúdico passou a ser reconhecido como traço essencial de psicofisiologia do comportamento humano. De modo que a definição deixou de ser o simples sinônimo de jogo (FIHO, et al. 2020).

Como a realidade do jogo ultrapassa a esfera da vida humana, é impossível que tenha seu fundamento em qualquer elemento racional, pois nesse caso, limitarse-ia à humanidade. A existência do jogo não está ligada a qualquer grau determinado de civilização, ou a qualquer concepção do universo. Todo ser pensante é capaz de entender à primeira vista que o jogo possui uma realidade autônoma, mesmo que sua língua não possua um termo geral capaz de defini-lo. A existência do jogo é inegável (LEONARDO e SCAGLIA, 2018).

O Lúdico mais que jogo é uma prática e reprodução do saber humano. Este contribui para um melhor desenvolvimento social e individual, essenciais para a aquisição da formação de conceitos. $\mathrm{Na}$ 
criança ajuda no desenvolvimento psíquico, psicomotor e cognitivo, já que ela pode através deste, conhecer melhor o mundo e interagir com ele, noção de espaço, distância, aprender a se relacionar, entre tantos outros são resultados desse conhecimento (FARIAS FABIANI, SCAGLIA e GAVIÃO DE ALMEIDA, 2016).

O jogo simbólico é a representação corporal do imaginário, e apesar de nele predominar a fantasia, a atividade psicomotora exercida acaba por prender a criança à realidade. Na sua imaginação ela pode modificar sua vontade, usando o "faz de conta", mas quando expressa corporalmente as atividades, ela precisa respeitar a realidade concreta e as relações do mundo real (VOGEL, et al. 2016).

A arte de brincar é uma forma de prazer e descoberta da criança, é uma forma que ela tem de expressar seus sentimentos e de novas descobertas, é a abertura da ideia de um princípio de que o mundo lhe pertence somente aos adultos. No entanto para Piaget, o jogo não era apenas uma forma de desafogo ou entretenimento para gastar as energias das crianças, mas sim meios que enriquecem e desenvolvem o intelecto delas (BERETTA, OLIVEIRA e VILELA, 2016).

$\mathrm{O}$ jogo passa a adquirir regras mais elaboradas através da socialização da criança; influenciando no desenvolvimento de suas atividades mentais de simbolização e, consequentemente, no processo de aprendizagem (BRAGA, et al. 2019).

O jogo é um fator fundamental para o desenvolvimento infantil, pois pela ludicidade a criança opera, trabalha as Zonas de Desenvolvimento Proximal, e aprende a agir (FIHO, et al. 2020).

\section{Ensino e aprendizagem}

Desde o ponto de vista em que processo de ensino - aprendizagem tem sido caracterizada de formas diferentes que vão desde a ênfase no papel do professor como transmissor de conhecimento, até as concepções que concebem o processo de ensino-aprendizagem com um todo integrado que destaca o papel do educando e como autor deste papel cabe a ele contribuir no processo de desenvolvimento cognitivo das diferentes áreas do conhecimento humano, trabalhando conteúdos pedagogicamente bem adaptados e elaborados para que os alunos consigam com mais facilidade adquirir os conhecimentos (MESSEDER NETO, 2019).

No ensino formal, a atuação do professor deverá estar primordialmente voltada para a utilização de metodologias que facilitem, nos seus aprendizes, a aquisição de uma estrutura cognitiva adequada, na qual os conceitos mais amplos 
das diversas áreas do conhecimento estejam claramente estabelecidos (OLIVEIRA, et al. 2018).

Uma das formas de facilitar esse conhecimento nas crianças é colocando-se no lugar delas e entender seu mundo para assim conseguir da maneira adequada passar o conhecimento que lhe é correspondido. É importante ressaltar que depende muito de a criatividade do instrutor criar alternativas de ensino para que as aulas sejam desejadas e não obrigadas, se tornando mais atraente, divertida, interessante e significativa tanto para eles como para os alunos (REGINATO, 2016).

A formação de conceitos não se inicia na escola, mas, muito antes, nas experiências da criança no mundo físico e social, cabendo ao ensino formal a importante missão de proporcionar condições para desenvolver na criança o processo de percepção generalizante (PEREIRA, et al. 2018).

Entretanto para que ocorra aprendizagem significativa é necessário que haja um relacionamento entre 0 conhecimento a ser aprendido e aquilo que o aprendiz já sabe, juntamente com uma coerência e sequência, para melhor abstração do conhecimento (FERREIRA, 2019).

\section{A utilização do lúdico no processo de ensino e aprendizagem}

Considerando que as atividades lúdicas podem contribuir para o desenvolvimento intelectual e psicomotor das crianças, a utilização de atividades motoras sub à forma de jogos para o domínio de conceitos e para o desenvolvimento de algumas capacidades psicológicas, tais como: memória, avaliação e resolução de problemas (OLIVEIRA, et al. 2018).

A atividade lúdica é o berço obrigatório das atividades intelectuais da criança, sendo, por isso, indispensável à prática educativa. O jogo é, portanto, sob suas duas formas essenciais de exercício sensório-motor e de simbolismo, uma assimilação do real a atividade própria, fornecendo a esta seu alimento necessário e transformando o real em função das necessidades múltiplas do eu (SARAIVA, et al. 2018).

O jogo educativo é proposto pelo adulto como uma intenção dirigida, seletivamente, para um ou vários fatores citados no terreno afetivo, cognitivo, social ou motor; preparação para a vida pessoal e social (ANUNCIAÇÃO, ARANTES e CHIRINÉA, 2016). Podemos dizer então que o jogo como meio educativo funciona porque, além de provocar prazer e satisfação aos jogadores, deixam uma marca que se acumula em forma de sentimentos, que os participantes vão 
assimilando e que um dia serão úteis (CASAGRANDE e RAMOS, 2017).

O jogo pode servir como estratégia metodológica já que se usado habitualmente ajuda a desenvolver atitudes e hábitos baseados na solidariedade, na tolerância, no respeito e da aceitação das normas de convivência social. A participação do adulto nos momentos lúdicos de uma criança pode propiciar as trocas entre gerações e a aprendizagem da construção de jogos e brinquedos populares; possibilitando a formação dos valores culturais do educando (INÁCIO, et al. 2016).

\section{As contribuições da ludicidade para o ensino-aprendizagem}

A inserção da ludicidade no cotidiano das turmas no Ensino Fundamental é um tema que vem sendo discutido no interior das escolas desde 2006, ano em que a Lei $\mathrm{n}^{\circ} 11.274$, que regulamenta o ensino fundamental de 9 anos, foi sancionada com o objetivo de assegurar às crianças um tempo maior de convívio escolar, maiores oportunidades de aprender e, com isso, uma aprendizagem com mais qualidade

A política de ampliação do ensino fundamental e a inclusão obrigatória das crianças de seis anos na Educação Básica possibilita aos educandos, especialmente os oriundos de famílias menos favorecidas financeiramente, que muitas vezes não contam com a inclusão de seus filhos na Educação Infantil, uma ampliação do tempo destinado à alfabetização, buscando, assim, respeitar os tempos individuais de cada criança, conforme indica o PNE (Lei $n^{\circ}$ 10.172/2001, meta 2 do Ensino Fundamental) (MESSEDER NETO, 2019). O principal argumento para a ampliação do Ensino Fundamental é oferecer maiores oportunidades de aprendizagem no período da escolarização obrigatória e assegurar que, ingressando mais cedo no sistema de ensino, as crianças prossigam nos estudos, alcançando maior nível de escolaridade (BECKER DA ROSA, GIACOMELLI e WERNER DA ROSA, 2016).

A Lei $n^{\circ} 10.172 / 2001$, em seu Art. $5^{\circ}$, deu aos Municípios, aos Estados e ao Distrito Federal o prazo de até 2010 para implementar a obrigatoriedade da oferta do Ensino Fundamental de nove anos. Entretanto, boa parte desses sistemas de ensino não fizeram uma adaptação progressiva, deixando a implementação desse modelo para o último momento. A adequação abrupta ao disposto na lei gerou muitos questionamentos, inseguranças e dificuldades na adaptação dos sistemas de ensino e das unidades escolares sob diversos aspectos: currículo, metodologias, mobiliário, concepções, entre outros (LEONARDO e SCAGLIA, 2018). 
Foi preciso pensar em um ambiente alfabetizador que considere a criança em sua condição real e conceber uma nova estrutura de organização dos conteúdos atenta ao perfil dessas crianças de seis anos, distinto das crianças de outras faixas etárias, sobretudo pela imaginação, curiosidade, movimento e desejo de aprender aliados à sua forma singular de conhecer o mundo por meio das situações lúdicas e das interações com os brinquedos (FARIAS FABIANI, SCAGLIA e GAVIÃO DE ALMEIDA, 2016).

O lúdico contribui para o processo de aprendizagem dos alunos por sua característica de envolvimento que desperta o interesse e o prazer pela aprendizagem. Não é o caso de afirmar que o processo de aprendizagem acontece somente por meio da ludicidade, mas que o envolvimento da ludicidade favorece e enriquece esse processo, tornando a aprendizagem mais prazerosa (RAMOS, SANTOS e LABURÚ, 2017).

Brincar é um espaço no qual se pode observar a coordenação das experiências prévias das crianças e aquilo que os objetos manipulados sugerem ou provocam no momento presente. Pela repetição daquilo que já conhecem, utilizando a ativação da memória, atualizam seus conhecimentos prévios, ampliando-os e transformando-os por meio da criação de uma situação imaginária nova. Brincar constitui-se, dessa forma, em uma atividade interna das crianças (COUTINHO, 2009).

Devido a sua relevância no universo infantil, os processos lúdicos de ensino e aprendizagem como suportes para o desenvolvimento das potencialidades afetiva, criativa, cognitiva e social da criança e, ainda, como elemento básico para um crescimento equilibrado e consciente, devem fazer parte do cotidiano escolar, especialmente das turmas de primeiro ano. Propor atividades que permeiem o mundo da criança de forma que a aprendizagem não seja esvaziada de sentido, inclui o lúdico como agente potencializador das práticas pedagógicas (LEAL KLEIN, LOCATELLI e NETO ZOCH, 2019).

É preciso ampliar o olhar para o novo. O uso do lúdico na escola é uma ferramenta metodológica capaz de promover o desenvolvimento da criatividade, da descoberta, uma vez que se propõe a romper com a reprodução mecânica, na medida em que implica oportunizar momentos de exploração, experimentação e expressão tão necessários ao desenvolvimento das crianças e à adaptação a novas situações, entre elas: o primeiro contato formal com o código escrito, no processo de alfabetização (CAF, et al. 2018).

Por meio de atividades que considerem a relevância de práticas lúdicas para o desenvolvimento das crianças, o 
processo de ensino e aprendizagem tende a acontecer de maneira mais natural, conduzindo os educandos ao conhecimento significativo e contextualizado com a realidade na qual estão inseridos (ESPINDOLA, 2017).

\section{Conhecer o lúdico na arte do ensino- aprendizagem}

A palavra lúdica é apresentada em diversas culturas como algo que se liga ao jogo, brinquedo, a diversão, contudo, sua definição é transcendental. São notórias as relações entre o jogo e arte presentes em nosso cotidiano e aprofundados na necessidade de comunicação. No século XVIII, a Arte era associada apenas ao belo, e nessa perspectiva que se ver na Arte uma relação direta do jogo e do Lúdico na Arte como ver o mais eficaz de todos os modelos sendo validada universalmente na própria razão (ARAÚJO, et al. 2017).

A oposição da razão e sensibilidade é esclarecida como no estado de jogo, onde apreciar o belo, a plenitude humana é desenvolvida tanto no cognitivo como nos sentimentos, pois o elo entre o pensamento, a concretude, a abstração, a percepção, a representação, a vitalidade, a forma, a natureza, a cultura são determinadas pelo logos e sentidos (HERMES RENATO, 2016).

O lúdico pode ser desenvolvido a partir do sentimento (BERG, et al. 2019), destacando o meio da personificação e da objetivação em drama, em termos mais esclarecidos é como a sensação necessita da auto- expressão para o visual e plástica. $\mathrm{Na}$ intuição, o lúdico possui como meio as atividades de construção em dança e música (ARAÚJO, SILVA SOUZA PARENTE e ARAÚJO, 2019).

Essas orientações podem quanto aos sentimentos, sensações, intuições, pensamentos, serem incorporadas aos jogos, brincadeiras, pois como elementos unidos formam na educação a harmonia em processos de aprendizagem de criar, descobrir, crescer, proporciona atividades em grupo, liberdade que não é tirada ou roubada, dada, contudo conquistada. Todo jogo é antes de qualquer coisa, uma atividade livre (IGLESIAS e SILVEIRA, 2019).

A origem do jogo não está instinto nem nos fins úteis, como concluem as explicações biopsicológicas ao contrário, permite a conservação de um espaço de liberdade, pois representa o afastamento das metas instintivas. E ainda, na liberdade do jogo se procriam certas experiências de ser no teatro, arte, festa, sonhos que de outra forma não seriam possíveis. Mesmo com toda a singularidade da Arte Lúdica há além da liberdade, existem regras, afinal sua raiz encontra-se na cultura sendo formada pela humanidade (INÁCIO, et al. 2016). transpõe essa liberdade quando o 
espectador transformado em participante é sujeito ativo a descobrir as inúmeras formas das suas obras, manipulando, interagindo. Assim a afinidade profunda entre ordem e jogo que este parece estar tão em larga medida ligado ao domínio da estética (CAF, et al. 2018).

Há nele uma tendência para ser belo lúdico. Este fator estético seja idêntico àquele impulso de criação de formas ordenadas que penetrasse o jogo em todos os seus aspectos. Os movimentos artísticos como Dadaísmo e Surrealismo possuem elementos lúdicos até mesmo na sua etimologia seja em determinado ambiente, espaço, regras do jogo o que pode acontecer ou não em meios culturais se revela como jogo do lúdico, enfim, participações que reproduzem o real permeado por regras situando-se fora do mesmo, evidenciando similarmente com a Arte (BATISTA e SIQUEIRA, 2019).

Um protótipo é comparar as brincadeiras de faz de conta, onde o indivíduo situa-se em outro momento, dimensão, sendo assim o faz também o artista. O estabelecimento relacional das várias artes e o jogo é enunciado passando da poesia, da música e da dança para as artes plásticas, verifica-se serem menos evidentes as relações com o jogo. A distinção entre as artes plásticas e as artes musicais corresponde grosso modo aparente ausência de características lúdicas nas primeiras em contraste com sua acentuada presença nas segundas por (OLIVEIRA, et al. 2018).

A imaginação não pode ser contra a lógica, o gerador contra o didático, o artístico contra o útil, como um reclamante ao qual se deve na adequação integrada dos sentidos perceptivos com o mundo externo do pessoal com a orgânica, uma integração que poderá ser alcançada pela metodologia da Educação. O lúdico na pré-escola, contudo em todos os níveis de educação básica, percebemos que dar coerência e direção ao lúdico significa convertê-lo em Arte (VOGEL, et al. 2016).

Assim o lúdico na Arte transcende não apenas em brincar, jogar, possibilita desenvolvimento pleno das produções significativas para a aprendizagem benéfica e liberta dos indivíduos, entretanto cabe aos mediadores educacionais propiciar além de todo aparato tecnológico, recriar perspectivas estéticas do lúdico, realizando releituras da verídica práxis social em outros segmentos do sentir e pensar (MESSEDER NETO, 2019). Empregar o lúdico na Arte como algo banalizado de elemento terapêutico, preenchimento de tempo ocioso é arriscado, pois o lúdico na Arte fomenta novos caminhos estratégicos para o ensino da Arte com apreensão de conteúdo, atividades, temáticas mais prazerosas e significativas para indivíduo. A educação nos diversos campos sociais 
segundo possibilita mediar às inúmeras construções saudáveis com a vida (BATISTA e SIQUEIRA, 2019).

Nesse aspecto, a ludicidade fornece fundamentos para uma educação vislumbrante futurística, menos traumatizante e mais promissora para a humanização tendo como objetivo restaurar e estabelecer uma vida digna, saudável a todo ser humano. Ocorre assim a transformação de conceitos de espaço artísticos estáticos, mas que possa estimular as ações através da ressignificação dos aspectos históricos, culturais, aperfeiçoando na modificação com o mundo e interior humano (INÁCIO, et al. 2016).

Neste sentido, não deveríamos ter nenhuma dificuldade em descrever como forma de brincadeira os modos plásticos de expressão, mas a tendência, tem sido dar uma interpretação muito mais restrita à atividade de brincar (FIHO, et al. 2020). O lúdico na Arte como em todas as áreas é uma ferramenta pedagógica fundamental para que ocorra o desenvolvimento da criatividade, iniciativa, autonomia e obtenção de vários conhecimentos, saberes, produzidos no decorrer da história da humanidade. O que a ludicidade traz de novo é o fato de que o ser humano, quando age ludicamente, vivencia uma experiência plena (BERETTA, OLIVEIRA e VILELA, 2016).
Com isso, queremos dizer que, na vivência de uma atividade lúdica, cada um de nós estamos plenos, inteiros nesse momento; nos utilizamos da atenção plena, como definem as tradições sagradas orientais. Enquanto estamos participando verdadeiramente de uma atividade lúdica, não há lugar, na nossa experiência, para qualquer outra coisa além dessa própria atividade (PEREIRA, 2017).

Tudo se concentra na união da potencialização da aprendizagem, afinal, está em um museu, centro cultural, exposições na escola, merece destaque para compreensão do mundo. Quando conceituamos o lúdico lembramo-nos de imediato apenas dos brinquedos, jogos, mas está mencionado nesse ensaio a capacidade de transformar imagens em expressão, enfim, permite a recriação de elementos prazeroso para obtenção do conhecimento (BRAGA, et al. 2019).

Sempre a ludicidade na arte ou contrário, permite o prevalecimento no tempo e se houve realmente significação sempre estará na mente do indivíduo, será lembrada, marcada de forma positiva, enfim, o lúdico na arte vai além do lazer, mas dar ênfase a criatividade, a imaginação, reorganizando o velho com fixação no agora com abertura para o novo. Estamos inteiros, plenos, flexíveis, alegres, saudáveis (REGINATO, 2016). 
Poderá ocorrer, evidentemente, de estar no meio de uma atividade lúdica e, ao mesmo tempo, estarmos divididos com outra coisa, mas aí, com certeza, não estaremos participando dessa atividade. Estaremos com o corpo aí presente, mas com a mente em outro lugar e, então, nossa atividade não será plena e, por isso mesmo, não será lúdica (LEONARDO e SCAGLIA, 2018). Portanto, os meios expressivos iniciam do âmbito lúdico, aprimorando a recriação real para elementos dimensionais que possam interagir com outros indivíduos criando elos aproximativos, outrora, dialéticos (BRAGA, et al. 2019).

\section{Aprender brincando o ensino- aprendizagem}

A maneira como a criança brinca reflete seu modo de agir. O lúdico na aprendizagem é capaz de desenvolver habilidades importantes, como atenção, imitação, memória e até imaginação. O cérebro humano se desenvolve por estímulos recebidos nos primeiros sete anos de vida. Por isso, é necessário incentivar todos os aspectos: cognitivo, motor e afetivo (COUTINHO, 2009).

A grande exposição tecnológica e imagética atual hiperestimula a área cognitiva, mas a criança não desenvolve a parte motora e afetiva. Por esse motivo, é indispensável que haja diversidade nas experiências

proporcionadas (ESPINDOLA, 2017).

O desenvolvimento dos pequenos deve acontecer em equilíbrio, levando em consideração o indivíduo como um todo. Quando este acontece apenas em uma área, as demais ficarão deficitárias, causando a falta de equilíbrio (FARIAS FABIANI, SCAGLIA e GAVIÃO DE ALMEIDA, 2016).

Através de brincadeiras, a criança tem apoio para superar dificuldades de aprendizado. Dessa forma, aprender brincando melhora não só o rendimento escolar, mas o ganho no conhecimento, na comunicação e também no modo psicoemocional (ANUNCIAÇÃO, ARANTES e CHIRINÉA, 2016).

Com os pais trabalhando em período integral, as crianças passam a maior parte do tempo em maternais e escolas. Assim, é importante que as instituições tenham um projeto pedagógico que leve a brincadeira como parte do aprendizado. As escolas que seguem esse modelo buscam fomentar a criatividade, explorar o mundo e se relacionar com o outro (BERETTA, OLIVEIRA e VILELA, 2016).

Além disso, atividades ao ar livre, como brincadeiras no parque, também são importantes. Uma vez que brincar na rua, com vizinhos e amigos, é praticamente inexistente nos dias de hoje. As escolas devem estimular esse tipo de exercício e 
preencher tal lacuna, visando o bom desenvolvimento dos alunos (LEONARDO e SCAGLIA, 2018).

As instituições de ensino com propostas tradicionais também precisam se adequar ao lúdico na aprendizagem para a rotina dos alunos. A BNCC afirma que a alfabetização se inicia na educação infantil, sendo que até 5 anos e 11 meses, os alunos devem ser capazes de fazer registros de palavras e textos, por meio da escrita espontânea (PEREIRA, 2017).

\section{CONCLUSÃO}

Através da teoria fundamentada nos livros, periódico científico, juntamente com a análise dos mesmos, foi possível estabelecer algumas considerações. Brincando, a criança se prepara para o futuro, aprendem espontaneamente, sem estresse ou medo de errar, mas com prazer pela aquisição do conhecimento e pelo prazer do próprio ato de brincar.

$\mathrm{O}$ ato de brincar também é importante já que estimula a autoestima do educando, que como papel de mediador precisa ter um olhar mais aguçado e interessado, fundamental para garantir o enriquecimento das brincadeiras, bem como a utilização das mesmas como ferramenta principal para o desenvolvimento biológico, psicológico, social, da linguagem, das relações sociais, dos fatores cognitivos,
Contudo, alguns professores, pedagogos e gestores escolares apresentam resistência em adotar recursos lúdicos por acreditarem que o jogo e o brinquedo perturbam a ordem, causando indisciplina e, por isso, infelizmente, tendem a separar o jogo e a brincadeira do trabalho escolar, deixando de envolver essas importantes ferramentas no processo do aprendizado, delegando-as apenas a poucos momentos de recreação (INÁCIO, et al. 2016).

afetivos, intelectuais e emocionais, legitimando o ato de brincar, como fator essencial nesta fase da vida e principalmente para o desenvolvimento humano.

Além disso, as situações lúdicas possibilitam o desenvolvimento da curiosidade, criatividade e autonomia, fundamentais para a maturidade emocional e o equilíbrio entre o psíquico e o mental.

Outro fator importante para o desenvolvimento psicossocial da mesma e que merece ser destacado é a participação da família no cotidiano escolar e nos momentos de brincar da criança, permitindo a adaptação desta ao ambiente no qual está inserida, abrindo de certa forma um "leque" para que seus filhos aprendam a se relacionar com o mundo em que vivem.

O lúdico é sua função terapêutica, pois através do brincar a criança libera suas 
angústias, medos, stress, possibilitando maior contato social entre o grupo, e experiências significativas entre os sujeitos, visto que estas se sentem mais seguras e estimuladas para explorar e construir uma

\section{REFERÊNCIAS}

ANUNCIAÇÃO, L. M. R. L.; ARANTES, H. A. G.; CHIRINÉA, A. M. Estratégias De Leitura: Caminhos Para a Inclusão. Journal of Research in Special Educational Needs, 2016. v. 16, p. 479482.

ARAÚJO, M. I. S. et al. Aplicação Do Jogo De Dominó Na Educação Fundamental I: Elucidando Os Numeros No Cotidiano Do Aluno. Revista Univap, 2017. v. 22, n. 40 , p. 384.

\section{ARAÚJO, S. S.; SILVA SOUZA} PARENTE, L. O. DA; ARAÚJO, A. D. Reading the cover of the book brincando de inventar in the perspective of grammar of visual design. Revista Brasileira de Linguistica Aplicada, 2019. v. 19, n. 3, p. 711-731.

BATISTA, C. A.; SIQUEIRA, M. Análise didática de uma atividade lúdica sobre a “instabilidade nuclear". Góndola, enseñanza y aprendizaje de las ciencias, 2019. v. 14, n. 1, p. 126-142.

BECKER DA ROSA, Á.; GIACOMELLI, A. C.; WERNER DA ROSA, C. T.

Caminhando pelo sistema solar: análise de uma atividade lúdica para estudar escalas astronômicas. Revista Iberoamericana de Educación, 2016. v. 72, n. 2, p. 9-22.

BERETTA, D. C.; OLIVEIRA, J. S.; VILELA, D. C. a Extensão Universitária E a Ludicidade Na Educação Infantil Contra Crueldade Animal E Violência Interpessoal. Revista Brasileira De aprendizagem mais significativa no ambiente escolar, pois sentem prazer em "descobrir o conhecimento" brincando.

Extensão Universitária, 2016. v. 7, n. 2, p. 139-144.

BERG, V. VAN DEN et al. Integrating juggling with math lessons: A randomized controlled trial assessing effects of physically active learning on maths performance and enjoyment in primary school children. International Journal of Environmental Research and Public Health, 2019. v. 16, n. 14, p. 1-13.

BRAGA, C. J. M. et al. Jogo de cartas como estratégia para o ensino de doenças autoimunes na graduação médica. Revista Eletrônica de Comunicação, Informação e Inovação em Saúde, 2019. v. 13, n. 3, p. 594-607.

CAF, B. et al. Ângela Barcellos Café 2. 2018. p. 1-25.

CASAGRANDE, N.; RAMOS, F. L. A Educação Física no contexto da educação do campo: a realidade do conteúdo jogo na escola. Motrivivência, 2017. v. 29, n. 51, p. 64.

COUTINHO, M. D. M. C. especiais: cegueira The ludicity in the teaching of fractions for students with special needs : blindness. 2009. v. 113, n. 2019, p. 103113.

ESPINDOLA, D. S. Atividade lúdica para o ensino de ciências como prática inclusiva para surdos Playful activity for science education with inclusive practice for the deaf Abstract. 2017. p. 485-498. 
FARIAS FABIANI, D. J.; SCAGLIA, A. J.; GAVIÃO DE ALMEIDA, J. J. O Jogo De Faz De Conta E O Ensino Da Luta Para Crianças: Criando Ambientes De Aprendizagem. Pensar a Prática, 2016. v. 19, n. 1, p. 130-142.

FERREIRA, S. S. EXPERIMENTAL NA PERSPECTIVA DA LUDICIDADE, 2019. p. 20-32.

FIHO, J. M. J. et al. A saúde do trabalhador e o enfrentamento da COVID19. Revista Brasileira de Saúde Ocupacional, 2020. v. 45, p. 435-438.

HERMES RENATO, H. Os Jogos Eletrônicos No Processo De Cognição De Surdos. Journal of Research in Special Educational Needs, 2016. v. 16, p. 799803.

IGLESIAS, T. G.; SILVEIRA, C. Ensino de ciências e educação infantil: um estudo pautado na reprodução interpretativa e cultura da infância. ACTIO: Docência em Ciências, 2019. v. 4, n. 3, p. 572.

INÁCIO, H. L. De D. et al. Práticas corporais de aventura na escola: possibilidades e desafios - reflexões para além da Base Nacional Comum Curricular. Motrivivência, 2016. v. 28, n. 48, p. 168.

LEAL KLEIN, C.; LOCATELLI, A.; NETO ZOCH, A. A Educação Ambiental por meio da ludicidade: uma proposta didática. Amazônia: Revista de Educação em Ciências e Matemáticas, 2019. v. 15, n. 33, p. 219.

LEONARDO, L.; SCAGLIA, A. J. Study on youth handball regulations: A documental analysis on the mandatory use of individual defensive system in under -12 and under-14 competitions. Journal of Physical Education (Maringa), 2018. v. 29, n. 1, p. 1-11.

MESSEDER NETO, H. D. S. O jogo é a excalibur para o ensino de ciências?: apontamentos para pensar o lúdico no ensino de conceitos e na formação do professor. ACTIO: Docência em

Ciências, 2019. v. 4, n. 3, p. 77.

OLIVEIRA, L. H. S. De et al. a Ludicidade No Ensino Da Geometria No $5^{\circ}$ Ano Do Ensino Fundamental. REAMEC - Rede Amazônica de Educação em Ciências e Matemática, 2018. v. 6, n. 3, p. 14-23.

PEREIRA, Í. S. P. O princípio de prática situada na aprendizagem da literacia: A perspectiva dos alunos. Educacao e Pesquisa, 2017. v. 43, n. 2, p. 393-410.

PEREIRA, V. S. et al. Os Jogos Das Crianças Nos Recreios Das Escolas Do $1^{\circ}$ Ciclo Do Ensino Básico Do Norte De Portugal. Movimento (ESEFID/UFRGS), 2018. v. 24, n. 3, p. 859.

RAMOS, E. D. S.; SANTOS, F. A. C. DOS; LABURÚ, C. E. O uso da ludicidade como ferramenta para o ensino de química orgânica: o que pensam os alunos.

ACTIO: Docência em Ciências, 2017. v. 2, n. 2, p. 119.

REGINATO HOSOKAWA, R.; CAMARGO BANDEIRA VILLELA, F. Agressividade Infantil No Contexto Escolar: As Possibilidades De Auxílio Proporcionadas Pela Ludicidade.

Colloquium Humanarum, 2016. v. 13, n. 04, p. 16-20.

SARAIVA, S. B. F. et al. Conhecimentos Ludopedagógicos na Aprendizagem da Natação Infantil. LICERE - Revista do Programa de Pós-graduação Interdisciplinar em Estudos do Lazer, 2018. v. 21, n. 4, p. 429-449.

VOGEL, A. S. et al. Ensinando polinômios através da ludicidade. REMAT: Revista Eletrônica da Matemática, 2016. v. 1, n. 2, p. 1-7 